\section{Lavado (higiene) de manos con agua y jabón}

\section{Washing (hygiene) with soap and water.}

\author{
Castañeda-Narváez JL, Hernández-Orozco HG
}

Las infecciones asociadas con la atención en salud son las que afectan a un paciente durante el proceso de atención en el hospital u otra instalación de atención sanitaria, que no estaban presentes ni se estaban incubando en el momento del ingreso. No obstante, la falta de higiene de manos del personal médico y enfermería antes y después de estar en contacto con un paciente es probablemente el único factor, relacionado con la transmisión de los microorganismos, común a la mayor parte de las infecciones. El cumplimiento de la higiene de manos es bajo.

El papel de las manos en la transmisión de gérmenes durante la atención clínica se identifico desde 1847 en Viena por Ignaz Semmelweis, observando una disminución de la sepsis puerperal y mortalidad materna cuando se llevaba a cabo este procedimiento. La higiene de manos es el término general que se aplica al lavado de manos con agua y jabón, que se realiza en los centros sanitarios para prevenir las infecciones asociadas con la atención en salud, aunque puede ser realizado con otras substancias antisépticas.

En octubre de 2002 se publicó la Guía para la higiene de las manos en el medio sanitario por los CDC (Centers for Diseases Control and Prevention) en el Morbidity and Mortality Weekly Report.

La Organización Mundial de la Salud lanzó en 2005, a través de la Alianza Mundial para la Seguridad del Paciente, el primer Reto Mundial en pro de la Seguridad del Paciente Una atención
Médicos adscritos al Departamento de Infectología, Instituto Nacional de Pediatría, México.

Recibido: 5 de agosto del 2016

Aceptado: 15 de agosto del 2016

Correspondencia

José Luis Castañeda Narváez drcastanedan@yahoo.com

Este artículo debe citarse como Castañeda-Narváez JL, Hernández-Orozco HG. Lavado (higiene) de manos con agua y jabón. Acta Pediatr Mex. 2016;37(6):355-357. 
limpia es una atención más segura, con el objetivo de reducir las infecciones asociadas con la atención en salud.

En México, en octubre del 2008, la Secretaría de Salud lanzó la campaña a nivel nacional: "Está en tus manos".

El objetivo de la higiene de manos es la limpieza de la mismas para reducir la carga bacteriana de las manos contaminadas.

Realice la higiene de sus manos con agua y jabón cuando éstas estén visiblemente sucias o contaminadas (sangre u otros fluidos corporales). La higiene con agua y jabón se debe realizar con una duración de 40 a 60 segundos con una fricción enérgica que abarque todas las superficies de las manos, iniciando con las palmas, dorso, espacios interdigitales, nudillos, dedos pulgares y finalmente las uñas. Numerosos estudios han demostrado que el incumplimiento de esta norma es más frecuente en los médicos y los paramédicos. Existen otras alternativas para la higiene de manos como el uso de soluciones a base de alcohol, clorhexidina, etc.; sin embargo, el uso de agua y jabón en países en desarrollo continúa siendo una opción por bajo costo. Por ello, se considera desde hace mucho tiempo que es la medida de prevención más eficiente para evitar las enfermedades infecciosas. En todo momento deberá descontaminar sus manos siempre considerando los "5 momentos básicos de higiene de manos", promovidos por la Organización Mundial de la Salud como una estrategia para elevar el cumplimiento de certificación de higiene. A continuación se describen esos 5 momentos:

1. Antes de tener contacto directo con el paciente (grado IB).

2. Antes de realizar procedimientos asépticos como insertar algún catéter venoso u otros dispositivos invasivos, aplicar medicamentos (grado IB).
3. Después del contacto con fluidos corporales o secreciones, membranas, mucosas, piel no intacta del paciente, aunque las manos no estén visiblemente sucias (grado IB).

4. Después del contacto con el paciente; ejemplo: tomar el pulso o la presión arterial o ayudar a levantar al paciente (grado IB).

5. Después del contacto con objetos inanimados en el área del paciente; ejemplo: equipo médico en zonas cercanas al paciente (grado IB).

El personal de salud también debe realizar higiene de las manos en las siguientes ocasiones:

1. Al inicio y término de la jornada laboral.

2. Antes de ponerse los guantes y al retirárselos.

3. Si cambia de una parte contaminada del cuerpo a una parte limpia durante la revisión del paciente.

4. Cuando estén visiblemente sucias o contaminadas con sangre $u$ otros líquidos corporales. (grado de evidencia II) (exclusivamente agua y jabón).

5. Cuando exista sospecha o prueba de exposición a microorganismos infectocontagiosos.

6. Antes de preparar o aplicar soluciones (momento 2 de la Organización Mundial de la Salud, antes de una tarea limpia)

7. Inmediatamente después de una exposición accidental con objetos afilados.

8. Antes de ingerir alimentos.

9. Antes y después de ir al baño (grado de evidencia II).

10. Al atender un paciente portador o con diagnóstico confirmado por C. difficile 
o Bacillus anthracis (exclusivamente con agua y jabón).

Desde el punto de vista administrativo se debe:

Contar con la infraestructura para que no falten los insumos básicos: jabón, toallas de papel secante, lavabos colocados estratégicamente y visibles.

Los estudios demuestran que el lavarse las manos con agua y jabón común reduce la cuenta bacteriana de la piel a 1.8 y $2.8 \mathrm{log}$; esto equivale a una eliminación de 90 a 95\% de los gérmenes que se encuentran en las manos contaminadas.

\section{Otros aspectos importantes para la higiene de manos}

a. Garantizar que existan la infraestructura y recursos de calidad, asegurando que no falten los insumos básicos.

b. Se deberán realizar talleres para incrementar el cumplimiento y la certificación en todo el personal sobre conocimientos y práctica de higiene de manos especialmente en zonas clasificadas como de riesgo.

c. Se deberá supervisar y vigilar el procedimiento retroalimentando a los usuarios y servicios. d. Se deberán buscar e implementar nuevas estrategias en forma continua para lograr el aumento en la adhesión a realizar la higiene de manos.

e. Se deberán realizar un indicador de cumplimiento y uno de certificación.

Debemos entender la prevención y el control de las infecciones hospitalarias o asociadas con la atención de la salud como responsabilidad individual y colectiva, pues sin la asimilación y la implementación correcta de los procedimientos ejecutados por quien presta el cuidado al paciente, ésta continuará siendo una traba a la calidad en la prestación de los servicios de salud y la seguridad del paciente ocasionando que el tratamiento proporcionado no logre el éxito esperado.

\section{LECTURAS RECOMENDADAS}

1. González SN, Hernández $\mathrm{OH}$, Castañeda NJL. Control de las Infecciones en Hospitales Pediátricos Asociadas a la Atención en Salud (IAAS), 3a ed. Trillas, 2016:239-241.

2. World Health Organization (WHO). Guidelines of hand hygiene in health care 2009. Disponible en: http://apps.who. int/iris/bitstream/10665/44102/1/9789241597906_eng. pdf Consultado 1/08/2016

3. Centers for Disease Control and Prevention. Guideline for hand hygiene in Health-care-Settings: Recomendations fof the Healthcare Infection Control Practices Adviisory Committee and the HICPAC/SHEA/APIC/IDSA Hand Higiene Task Force. MMWR 2002Oct;5(16):1-45.

4. Lanzamiento de campaña "esta en tus manos" Disponible en: http://www.conamed.gob.mx/prensa/2008/campania_en_tus_manos.php Consultado 1/08/2016 